\title{
Enneking Metastasis
}

National Cancer Institute

\section{Source}

National Cancer Institute. Enneking Metastasis. NCI Thesaurus. Code C140266.

A description of malignant mesenchymal tumors based on presence or absence of metastasis. 